\title{
DISCUTINDO A BASE NACIONAL COMUM CURRICULAR BRASILEIRA: uma análise sobre Educação Inclusiva no ensino de Ciências da Natureza
}

Thalisia Cunha dos Santos

Universidade Federal Fluminense - UFF

Johana Marcela Concha Obando

Universidade Federal Fluminense - UFF

Diana Negrão Cavalcanti

Universidade Federal Fluminense - UFF

\begin{abstract}
Resumo
A Base Nacional Comum Curricular (BNCC) trouxe diversos desafios no campo da educação, principalmente na Educação Especial, isso porque há poucas menções no documento sobre essa modalidade de ensino, levando a crer que a base criada para todos os alunos, não foi pensada para Pessoas com Deficiência, Transtornos Globais do Desenvolvimento (TGD) e Altas habilidades/Superdotação. Quando se trata do ensino de Ciências, os desafios são ainda maiores, uma vez que a reforma do ensino médio uniu as disciplinas Química, Física e Biologia em um único itinerário formativo, podendo levar a déficits de aprendizagens dos alunos com ou sem necessidades educacionais específicas. Visando compreender a nova realidade, o presente estudo propôs uma revisão bibliográfica de cunho qualitativo e quantitativo sobre a BNCC, a fim de se obter o aspecto geral do rumo da Educação Inclusiva no Brasil e as possíveis implicações no ensino de Ciências. Os resultados desta pesquisa deixam clara a negligência da BNCC no que diz respeito à modalidade de Educação Especial, visto que nossas análises corroboram a exclusão desta na versão final do documento. Ademais, aponta-se a falta de estudos sobre as interfaces entre Ciências da Natureza, Educação Especial e BNCC, convocando, assim, os profissionais da área na busca de práticas inclusivas para diminuir os impactos do documento no percurso acadêmico desses estudantes.

Palavras-chave: BNCC; Educação Especial; Educação Científica.
\end{abstract}

\section{Abstract}

The National Common Curricular Base (BNCC/Brazilian abbreviation) brought several challenges in the field of education, especially in Special Education because there are few mentions about it, leading to think that the BNCC, aimed at all students, rejected People with Disabilities, Global Developmental Delays (GDD), and High Abilities/Giftedness. When it comes to science education, the challenges increase since the reform of high school put together the subjects Chemistry, Physics, and Biology in a single formative program, which may lead to learning deficits for students with or without special educational needs. So, this study proposed a bibliographic qualitative and quantitative review about the document to obtain the global aspect of the course of Inclusive Education in Brazil and the possible implications in science teaching. The results of this research make explicit that the BNCC neglected the Special Education modality since our analyzes confirm its exclusion in the final version of the document. Furthermore, studies on the interfaces related to Natural Sciences, Special Education, and BNCC are scarce, calling on professionals in the area to seek inclusive practices to reduce the impact of the document on their students' academic path.

Keywords: BNCC; Special education; Science education. 


\section{Introdução}

A última versão da Base Nacional Comum Curricular (BNCC) foi homologada em dezembro de 2018, trazendo uma série de desafios e questionamentos referentes à sua implementação e sucesso. Vários autores têm se dedicado a analisar os aspectos no campo de políticas públicas e currículo (COSTA; LOPES, 2018; COSTA; SILVA, 2019; FERREIRA, 2016; FREITAS, 2014; FREITAS; SILVA; LEITE, 2018; MACEDO, 2015, 2016, 2017; SILVA; MELLO, 2018), do campo pedagógico (BRANDÃO; TREVELIN, 2017; CÂNDIDO; GENTILINI, 2017; GARCIA-REIS; GODOY, 2018) e os referentes à formação docente (FISTAROL; FICHER; WENRLICH, 2019; LEMOS, 2019; MARTINS; TOSTES; MELLO, 2018; AGUIAR, 2017). Apesar dos diversos trabalhos publicados, poucos foram dedicados ao campo da Educação Inclusiva (EI) (FERREIRA; MOREIRA; VOLSI, 2020; ORRÚ, 2018; MERCADO; FUMES, 2017) e lacunas na base curricular brasileira.

Sabendo disso, o presente trabalho buscou obter um panorama sobre a BNCC, através de uma revisão bibliográfica nas principais bases de dados, para avaliar a temática de inclusão presente no documento, analisando, qualitativa e quantitativamente, artigos e documentos oficiais encontrados; sobre o Censo da Educação Básica de 2019 e sobre versões da BNCC, divulgadas pelo Ministério da Educação, tentando responder às seguintes questões: (i) Para que tipo de aluno a BNCC foi pensada? (ii) Quais caminhos tortuosos as Pessoas com Deficiência, TGD e Altas habilidades/Superdotação, enquanto estudantes, poderão percorrer, caso não haja um movimento de resistência por parte dos profissionais da educação? (iii) $\mathrm{O}$ itinerário de Ciências da Natureza, presente na BNCC, contempla a modalidade da Educação Especial (EE)?

Para responder às questões, o artigo foi dividido em duas seções: fundamentação teórica acerca da BNCC, sob um olhar de alguns dos principais artigos publicados e os tratamentos qualitativos e quantitativos dos dados gerados nessa revisão. A primeira seção apresenta os aspectos legais, histórico e as principais críticas da BNCC, usando como referência alguns autores que se debruçaram sobre o tema (FREITAS; SILVA; LEITE, 2018; GIROTTO, 2017, 2019; MACEDO, 2015, 2016, 2017); a Educação Inclusiva e a BNCC (FERREIRA; MOREIRA; VOLSI, 2020; ORRÚ, 2018; MERCADO; FUMES, 2017) e um breve olhar sobre ensino inclusivo ${ }^{1}$ de Ciências da Natureza no Ensino Médio sob a perspectiva da Base. Já na segunda parte, são apresentados gráficos, mapa de similitudes e nuvem de palavras para sustentação da discussão elencada. Dessa forma, o artigo tem o intuito de trazer à tona uma discussão sobre as perspectivas no ensino de Ciências da Natureza e Educação Especial sob um olhar da atual BNCC.

\section{Metodologia}

Este estudo constitui-se de uma pesquisa bibliográfica de natureza qualitativa e quantitativa, analisando os artigos publicados entre 2014 e abril de 2020, utilizando os seguintes termos: Base Nacional Comum Curricular, BNCC e Common National Curricular Base, coletando apenas os artigos publicados no Brasil, usando as seguintes bases de dados: Scielo (47 artigos), Scopus (33 artigos) e Web of Science (68 artigos). A escolha dessas palavras é justificada pelo interesse de compreender como os autores têm abordado a BNCC e a perspectiva inclusiva no ensino de ciências. Vale mencionar que a busca dos termos na língua inglesa foi realizada para obtenção de publicações internacionais. Ainda foram realizadas buscas com os termos supracitados em concomitante com as palavras ciências, EE, EI e inclusão. Entretanto, como os artigos encontrados já haviam sido coletados nas buscas anteriores, optou-se por não registrar tais dados.

A primeira etapa consistiu na remoção dos artigos duplicados (20 artigos); em seguida, foi realizada a leitura completa dos artigos selecionados (128 artigos) para posterior agrupamento nas seguintes áreas de conhecimento: Ciências da Natureza (CN), Ciências Humanas, Língua Portuguesa, Língua Inglesa, Matemática, Ensino Religioso, Artes, Educação Física, Tecnologias Digitais da Informação e Comunicação (TDIC), Ensino Médio, Ensino Fundamental, Formação de Professores, Políticas Públicas e Educacionais, 
Currículo, Educação de Jovens e Adultos (EJA), Educação Especial, Temas Transversais e Outros.

Foram buscadas informações em sites e órgãos públicos, os quais deram suporte aos procedimentos de investigação e da análise, tais como: Ministério da Educação (MEC), BNCC, Instituto Nacional de Estudos e Pesquisas Educacionais Anísio Teixeira (INEP) e outros. Dessa forma, a pesquisa pode ser classificada como qualitativa de tipo documental que visa interpretar um fenômeno social inserido num contexto para criar formas de compreendê-lo (KRIPTA; SCHELLER; BONOTTO, 2015). A leitura dos artigos selecionados propiciou a sustentação teórico-metodológica apresentada na primeira seção deste trabalho.

A segunda seção apresenta uma série de análises qualitativas e quantitativas. Para melhor compreensão, serão explicitadas aqui em subcategorias: i) Apresentação da EE no contexto atual do Brasil; ii) Resultados quantitativos da revisão bibliográfica; iii) Análise por mapa de similitudes e nuvem de palavras dos artigos da revisão e iv) Busca de palavras-chave na BNCC.

A primeira subcategoria consta dos gráficos com dados provenientes do Censo da Educação Básica de 2019 do INEP (2019). Para tal, foram coletados os números de matrículas da EE dos anos de 2015 até 2019, na modalidade do Ensino Médio (EM) e o número de matrículas distribuídas na rede privada e pública. Em relação ao último, foram agrupadas todas as redes do setor público: federal, municipal e estadual. Esses dados foram convertidos em valores percentuais para melhor compreensão dos resultados.

Os resultados da revisão bibliográfica foram apresentados a partir de gráficos de número de artigos por ano de publicação, base de dados em que o artigo foi publicado e área de conhecimento, sendo possível ter uma visão geral dos artigos publicados sobre a BNCC ao longo dos últimos anos.

Foi utilizado também o software Iramuteq ${ }^{\circledR}{ }^{2}$, conforme discutido por Camargo e Justo (2013), para realização de um tratamento quali-quantitativo aos dados, gerando, por meio do processamento, uma nuvem de palavras e mapa de similitude. Para tal, foi criado um banco de dados com os resumos de todos os artigos que foram codificados e inseridos no software. Para a formação da nuvem de palavras, foi delimitado um número de palavras cujo valor igual a 50 - é suficiente para descrição dos principais temas que compõem os resumos dos artigos. Cabe ressaltar que o software Iramuteq ${ }^{\circledR}$ só faz registro das palavras que foram mencionadas pelo menos três vezes.

Para gerar o mapa de similitude, foi necessária a exclusão dos conjuntos lexicais de maior recorrência, pois como se enquadram na temática da BNCC, em geral, os resumos apresentam as palavras Base, Nacional, Comum, Curricular e educação. Essa exclusão é necessária para que seja possível gerar um mapa de similitude compreensível, senão ver-seia um emaranhado de palavras cruzadas com inúmeras correlações passíveis de más interpretações.

Além disso, foi realizada uma busca pelas palavras-chave, nas quatro versões da BNCC, publicadas pelo Ministério da Educação (BRASIL, 2015; 2016; 2017; 2018). Tentou-se rastrear as palavras-chave ligadas à EE e Pessoas com Deficiência, Transtornos Globais do Desenvolvimento e Altas Habilidades/Superdotação: deficiência, deficientes, acessíveis, acessibilidade e EE, buscando adquirir informações qualitativas do documento da BNCC que poderiam contribuir de alguma forma com os objetivos deste trabalho.

\section{A Base Nacional Comum Curricular}

A BNCC é um documento normativo que define as habilidades e competências essenciais para a formação integral dos estudantes (BRASIL, 2018). Até chegar à versão homologada em 14 de dezembro de 2018, a BNCC percorreu um longo caminho. Mas antes de entender sua elaboração, é necessário conhecer os aspectos legais que levaram a isso (Figura 1). Macedo (2015), em seus estudos, descreve que a necessidade de uma base comum em nível nacional estava prevista na Constituição Federal de 1988 (BRASIL; 1988) e na Lei de Diretrizes e Bases da Educação Nacional (LDBN) (BRASIL, 1996). A LDBN estabelece que os currículos da educação infantil, do ensino fundamental e do EM devem ter base 
nacional comum para que todos os estudantes tenham pleno acesso à formação humana integral e à construção de uma sociedade justa, democrática e inclusiva (BRASIL, 1996). Desde a década de 90 é almejado um currículo unificado, porém, só após o sancionamento da Lei ${ }^{\circ} 13.005$ (2014) que intitula-se Plano Nacional de Educação (BRASIL, 2014; KIPPER; OLIVEIRA; GOMES, 2019) e por ação de órgãos empresariais que a necessidade da base ganha força (FREITAS, 2014; LIMA; MACIEL, 2018).

Figura 1. Linha temporal das principais mudanças e legislações da educação básica brasileira a partir da LDBN.

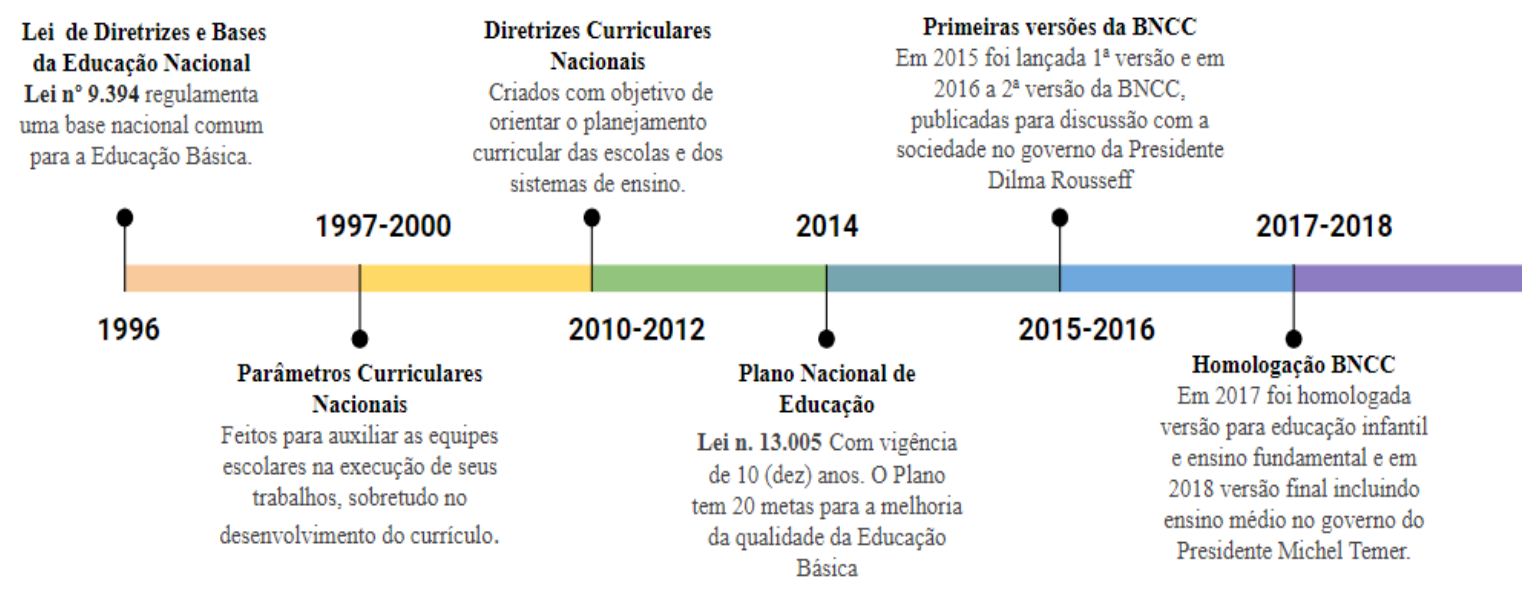

Fonte: Adaptado do histórico apresentado no site oficial da BNCC. Disponível em: http://basenacionalcomum.mec.gov.br/historico Acesso: 10 jun. 2020.

Bem antes da efetivação de uma base, o MEC apresentou alguns documentos norteadores: os Parâmetros Curriculares Nacionais (PCNs), ainda na década de 90, e as Diretrizes Curriculares Nacionais (DCNs), lançadas a partir de 2010. Esses documentos abordam o EM em diferentes aspectos e contam com uma série de reformas na educação brasileira, entretanto, não se trata de um currículo nacional, como a atual BNCC. O grande problema de uma base nacional é que quando se trata de um país tão amplo em extensão física, cultural, social e econômica, é possível que alguns grupos não tenham pleno acesso à educação para exercício da cidadania (BRANCO; ROYER, GODOI BRANCO, 2018; MARCONDES, 2018; NETO, 2014).

O momento de sua formulação é considerado conturbado (GONÇALVES; MACHADO; CORREIA, 2020) e gera desconforto aos pesquisadores que têm se dedicado a estudá-la, isso porque foi confeccionada em dois momentos políticos distintos, o que acaba por gerar diferenças ideológicas e de objetivos. Foi iniciada no governo da Presidente Dilma Roussef (2014-2016), gerando as duas primeiras versões amplamente debatidas pela comunidade acadêmica, com profissionais da educação e a sociedade (MARCONDES, 2018). Porém, com o processo de impeachment, a Base passou a ser redigida e influenciada por grupos empresariais e conservadores, por autoridade do então presidente Michel Temer (20162018), o qual assumiu o poder sob processo considerado ilegítimo por muitos (LIMA; MACIEL, 2018; COSTA; SILVA, 2019). Ou seja, o contexto favoreceu as discrepâncias entre os interesses do capital, dos acadêmicos, alunos e professores.

Além do processo histórico de formulação, têm sido levadas discussões sobre sua definição, significado, aplicabilidade e suas relações como currículo. O chamado currículo pode ser definido como um guia norteador com os conteúdos que devem ser ensinados em ordem cronológica e com coerência para atingir a aprendizagem (SILVA, 2010). Entretanto, apesar de apresentar essa estrutura, a BNCC não se define como currículo, mas sim como balizador da qualidade da educação no Brasil, estabelecendo um patamar de aprendizagem e desenvolvimento para todos (BRASIL, 2018).

Apesar de apresentar-se como documento norteador, a BNCC dá uma falsa ilusão de independência às escolas ao atribuir às secretariais a autonomia de elaboração de seus currículos, mas, ao mesmo tempo, deixa explícito quais competências, conhecimentos e habilidades que os/as estudantes devem desenvolver ao longo do percurso escolar, fazendo com que sejam obrigatórios os conteúdos presentes na base. Ora, se a finalidade da BNCC é 
fundamentar e nortear os demais currículos, então considerá-la como tal é importante para compreensão total da sua finalidade (GONÇALVES; MACHADO; CORREIA, 2020). Pensar dessa maneira, leva à seguinte implicação: Por que não explicitar a BNCC oficialmente como currículo? Porque, assim, produz-se uma lógica de responsabilização da escola e dos docentes pelos futuros fracassos, exaurindo a culpa do poder público (FREITAS; SILVA; LEITE, 2018).

Então, partindo do princípio de que a BNCC é um currículo, devem ser levadas em consideração as disputas de poder envolvidas na sua confecção e, como qualquer ringue, um lado sempre acaba perdendo. A pergunta a ser levantada neste momento é: Quais grupos deixaram de ser lembrados e favorecidos? Almeida e Batista (2016) ajudam a refletir sobre o desfavorecimento de certos grupos em detrimento de outros nas relações do currículo ao afirmarem que, nas disputas de poder que ocorrem na sua formulação, grupos subjugados são submetidos às suas próprias condições de desigualdade social e ajudam a manter as relações de poder preexistentes (ALMEIDA; BATISTA, 2016).

Existe incomunicabilidade entre o que a Base propõe e o público-alvo que vai contemplar. O documento faz alusão à formação de cidadãos, indagando pelo fato de ter sido gestada pela e para a sociedade brasileira, mas deixa lacunas ao não se referir a certos grupos minoritários, pessoas transgênero, por exemplo, ao excluir da base assuntos sobre sexualidade, orientação sexual e gênero (FREIRE, 2018; RIOS; VIEIRA, 2020; PESSOA; HOELZIE, 2017), sobre Pessoas com Deficiência (PcD), TGD e Altas Habilidades/Superdotação (ORRÚ, 2018), entre outros. Além disso, há um descontente discurso sobre uma falsa igualdade social e respeito às diferenças, sem meios e garantias de que sejam solucionadas tais questões. (ABRAMOWICZ; TEBET, 2017). Ademais, pouco se trata do conceito de qualidade e das variáveis que influenciam o processo de ensino e aprendizagem.

As mudanças chegaram às escolas de forma espantosa, atingindo alunos e professores que acabaram recebendo um turbilhão de mudanças e descontinuidades, as quais terão que se adaptar para atingirem o desempenho esperado pelos órgãos reguladores (PASSOS; NACARATO; 2018; PEREIRA, 2019). É notável que não houve a preocupação em como a escola sustentará as diversas alterações em seus currículos com a falta de infraestrutura, desconsiderando, também, a desigualdade (de todas as ordens) presente no ensino público do Brasil. Certamente, as escolas privadas possuem meios para investir na qualificação dos profissionais que lidarão com o documento, terão melhores infraestruturas e mobilidade para diminuir ou melhorar os déficits do espaço educacional, levando em consideração que o currículo em vigor foi pensado exatamente para essa classe hegemônica. Freitas (2014) sugere que os reformadores empresariais estão diretamente ligados a essa polarização. Em seus estudos sugere que a padronização entre os diferentes grupos sociais e indivíduos permite o fortalecimento do controle dos grupos menos privilegiados e que o fracasso desses grupos será tomado como responsabilidade da escola e não do sistema.

Macedo (2015) deixa claro que a promessa de igualdade universal na política e na educação jamais será cumprida, visto que a universalização gera involuntariamente a exclusão. Frangella (2016, p. 74) ainda argumenta que "a igualdade vista como horizonte implica que a diferença seja subsumida, num ideário de democracia que se ampara numa ideia de uniformização como via para equidade". A diferença está atrelada à diversidade sem a qual não pode ser atingida a partir de uma base comum (SANTOS, 2017); a uniformização acaba por gerar uma expectativa de um sujeito universal, estabelecendo velocidade de avanços e, consequentemente, um ritmo de aprendizagem, fadada à exclusão (FRANGELLA, 2016; FREITAS, 2014; MACEDO, 2015).

Além da falsa ideia de igualdade, o documento apresenta uma configuração de currículo oculto (SAVIANI, 2016), ou seja, contém aspectos escondidos/implícitos que podem contribuir de forma negativa à comunidade escolar. Essa ideia é reforçada por Freitas e colaboradores (2018) que, ao referirem-se à BNCC, descrevem diretrizes invisíveis, contidas no documento, uma delas é que a BNCC não diz como fazer aquilo que ela pede e, outra, é o marco regulatório para controle das responsabilidades. Os autores também deixam claro a falta de suporte metodológico de como trabalhar as habilidades a serem desenvolvidas, a ausência de discussões sobre inclusão e o discurso dominante ao desconsiderar a pluralidade brasileira. 
Em relação à implementação nas escolas, é certo que as escolas públicas não estão estruturalmente preparadas para a reforma; antes de ter sido pensada a Base em si, era necessário repensar a escola. O sucesso da escola está ligado ao ambiente físico, seus recursos, à qualificação dos seus profissionais. Nesse sentido, seria necessário e válido que os órgãos públicos oferecessem estruturas adequadas às escolas, investissem na formação e valorização dos profissionais da educação, para que os alunos e alunas possam ser acolhidos num espaço que favoreça a aprendizagem e os docentes estejam aptos a cumprirem seu papel (SANTOS, 2017).

Essas diretrizes ajudam a responder a primeira pergunta deste trabalho: Para que tipo de aluno a Base foi pensada? A BNCC, assim como argumentam (ABRAMOWICZ; TEBET, 2017; FREITAS, 2014; MACEDO, 2015, 2016, 2016; SANTOS, 2017), foi criada e pensada para um sujeito universal de classe dominante com um ritmo de aprendizagem conivente com o que o documento se propõe e sem déficits cognitivos. Dessa maneira, ao considerar a BNCC como currículo, percebe-se que os grupos minoritários ficam à mercê de lacunas no processo de aquisição do conhecimento e no que diz respeito ao exercício pleno da cidadania, o que tanto almeja aos demais grupos.

\section{Educação Especial e a BNCC}

É importante esclarecer, antes de iniciar o debate sobre BNCC e EE, o que vem a ser Educação Especial e Educação Inclusiva, pois são termos relacionados encontrados frequentemente nos textos, mas que possuem significados distintos. O primeiro termo diz respeito a uma modalidade de ensino transversal ao ensino regular e o segundo é uma perspectiva trazida e proposta à escola como modo de garantir os direitos de todos os cidadãos, abarcando assim todas as minorias (GLAT; PLETSCH; FONTES, 2007). Embora o termo EI seja amplo, o enfoque deste trabalho é a inclusão dos estudantes com deficiência, TGD e altas habilidades/superdotação.

Segundo Orrú (2018), inclusão significa ir muito além das legislações e categorias, é o conjunto de meios e ações que expandem os espaços e, reinventa-se, fazendo com que as diferenças sejam compreendidas e não acentuadas. Incluir é garantir que todos os indivíduos participem ativamente na sociedade, que sejam aceitos e respeitados pelo que são (FREIRE, 2008). Podemos ainda dizer que inclusão é um movimento de âmbito educacional, social e político que deve garantir igualdade e direitos humanos a todos os cidadãos (SANCHES; TEODORO, 2006).

Nesse princípio, incluir é reconhecer e compreender a diversidade de forma a gerar espaços acolhedores e sem discriminações. Apesar do progresso no campo da e EI, há muita dificuldade em se obter espaços educacionais realmente inclusivos, principalmente tratandose da educação pública no Brasil. Visando contribuir com esse debate, a seção terá como aporte teórico dados sobre a EI baseados em trabalhos de Orrú (2018), Mercado e Fumes (2018) e Ferreira, Moreira e Volsi (2020). É importante ressaltar que esses trabalhos foram publicados nos dois últimos anos, mostrando a emergência nas discussões sobre EI e BNCC. Nesse sentido, o presente artigo configura-se como mais um estudo abordando a temática EI, fazendo parte desse crescente interesse.

Os trabalhos publicados têm como eixo central a discussão sobre a inclusão no campo das diferenças. Para Orrú (2018), o movimento de inclusão só ocorre quando a diferença é vista como seu par, ambas só existem no campo da própria diferença e, sem ela, não há como ter políticas inclusivas (ORRÚ, 2018). Esse é um grande problema epistemológico da BNCC que tenta unificar as diferenças tornando-as únicas e indistintas, quando, historicamente, foram construídas de formas diferentes (ABRAMOWICZ; TEBET, 2017). Esse cerceamento da diversidade, leva à exclusão de grupos minoritários, principalmente PcD (COSSETIN, 2017), pois ao universalizar o sujeito, criando habilidades e competências, os estudantes que não atingirem os objetivos acabam virando a sobra do sistema. Esse processo de normalização social cria por si só um vácuo entre aqueles que se adaptam aos padrões e aqueles que não foram contemplados por uma política inclusiva, levando à exclusão total e marginalização desses sujeitos (MELO; MAROCHI, 2019). 
Vale mencionar que, nas duas primeiras versões da BNCC apresentadas à sociedade, houve a preocupação em propor uma abordagem curricular na perspectiva EE, como garantia da inclusão de alunos e alunas com deficiência, TGD e altas habilidades/superdotação (MERCADO; FUMES, 2017) como prevê a Constituição Federal (BRASIL, 1988) e a LDBN. Na segunda versão, por exemplo, é explicitado que a EE contempla a identificação e a eliminação das barreiras, principalmente as de acesso ao conhecimento, deslocando o foco da condição de deficiência dos estudantes para a organização e a promoção da acessibilidade aos ambientes escolares em todas etapas e modalidades, visando à autonomia e à independência dos educandos (BRASIL, 2016).

O estranhamento por parte dos estudiosos da área é a abrupta mudança na terceira e quarta versão da BNCC, quando houve a eliminação da modalidade EE do documento oficial. Ferreira e colaboradores (2020) citam a ausência da abordagem com relação à EI, por meio da não explicitação dos envolvidos e as poucas menções no que tange à modalidade citada.

Apesar das leis e políticas educacionais, a inclusão no espaço escolar acaba de sofrer mais um golpe, devido ao caráter universalista e excludente da BNCC (MERCADO; FUMES, 2017). Os estudantes com deficiência, TGD e altas habilidades/superdotação são cotidianamente privados do acesso ao conhecimento e à integral cidadania, pois estão à deriva de quem possa pensar e falar por eles, uma vez que não foi concedido espaço de participação ativa na construção do documento. Assim, a Base Nacional deveria ter envolvimento direto dos indivíduos com deficiência, TGD e altas habilidades/superdotação para que estes sejam detentores da sua própria voz e lutas.

A Lei Brasileira de Inclusão à Pessoa com Deficiência (BRASIL, 2015) aponta formas de como garantir o pleno acesso ao currículo em condições de equidade, mas o panorama da BNCC não apresenta garantias para oferecer esse tipo de educação. Tendo em conta o exposto, nota-se a grande dificuldade de se estabelecer uma EI com a nova Base. Uma forma de diminuir o impacto do documento na vida desses estudantes é através do movimento de resistência por parte dos profissionais da educação, baseando suas aulas em pedagogias inclusivas e acolhedoras. Porém, essas ferramentas, quando não alinhadas à participação ativa da sociedade e a políticas públicas, não vão garantir uma inclusão no espaço educacional.

\section{Um olhar sobre as Ciências da Natureza no Ensino Médio sobre perspectiva da BNCC}

O Ensino Médio configura-se como etapa fundamental da educação básica e, por isso veementemente é atacado por grupos empresariais e conservadores, pois acabam formando a grande massa de trabalhadores tão almejados pelo capital (FREITAS, 2014). Esses grupos acabaram por auxiliar no processo de reformulação do Ensino Médio através de Medida Provisória e posterior homologação como Lei n ${ }^{\circ}$ 13.415/2017 (PONCIANO et al., 2019; BRASIL, 2017). Das mudanças oriundas da lei, uma das mais importantes foi realizada no campo das Ciências da Natureza e suas Tecnologias, que agrupa as disciplinas Química, Física e Biologia em um único itinerário formativo (MARCONDES, 2018).

Nessa lógica, as ciências naturais devem ser ensinadas de forma interdisciplinar com temas ligados aos campos de tecnologia, processos produtivos e sustentabilidade, de forma a desenvolver o pensamento crítico e analítico dos alunos (BRASIL, 2018). Se o objetivo fundamental da BNCC é a efetivação de uma educação democrática, isto é, aquela que visa formar pessoas para exercício da cidadania, então a Base deve transpassar pelo letramento científico em seus múltiplos aspectos, desde a compreensão de conceitos à construção do conhecimento e história da ciência (MARCONDES, 2018).

Embora a proposta pareça coerente, a diretriz invisível (FREITAS; SILVA; LEITE, 2018) presente no itinerário de ciências é sobre a forma que será colocada em prática. A base não apresenta uma proposta pautada em aspectos pedagógicos que digam como efetivar tal agrupamento, dificultando o processo de implementação. Parte dos conteúdos de física, química e biologia foram excluídos e não foi exposto o porquê de privilegiar um conteúdo em detrimento de outro, fazendo com que se questionem novamente as questões de currículo: Como pode alguém dizer que ciência é essencial para o outro saber? (NEIRA; JÚNIOR; 
ALMEIDA, 2016). Como se não bastassem as inúmeras habilidades e competências, há a incompatibilidade entre o que a base anuncia e o que realmente propõe; nem mesmo é explicitado o porquê de agregar todas as disciplinas de ciências em um único itinerário formativo. Para mais do que foi exposto, uma outra questão a ser analisada é a perda da identidade das disciplinas, visto que unir tantas áreas em um mesmo grupo, pode fazer com que cada uma oculte suas peculiaridades e sua função social (PORTELA, 2018).

As $\mathrm{CN}$ constituem-se com componentes fundamentais para o enfrentamento de problemas que envolvam o conhecimento científico, os princípios éticos e morais relacionados à aplicação da ciência e tecnologia (SILVA; MARCONDES, 2010). Por isso, quando se leva em consideração o fato de que muitos conteúdos foram excluídos no agrupamento proposto, é preciso pensar se de fato a BNCC visa à formação de um aluno crítico e atuante na sociedade (MARCONDES, 2018).

Os trabalhos que abrangem o campo das $\mathrm{CN}$, sob a perspectiva da $\mathrm{BNCC}$, abordam apenas uma única disciplina do itinerário formativo; não foram pensados para Pessoas com Deficiência, TGD e Altas Habilidades/Superdotação ou, ainda, fazem parte do campo de discussão de currículo (MARCONDES, 2018; SABINO et al., 2019; SILVA NETO; FREIRE JÚNIOR, 2017; VIEIRA; MORAIS; GODINHO-NETO, 2019).

Atualmente, há estudos que desenvolveram metodologias inclusivas na área das $\mathrm{CN}$, porém a BNCC não contempla pontos de metodologias inclusivas e didáticas. As políticas de currículo não podem ser alteradas imediatamente, logo a BNCC estará em vigor e ficará por um longo tempo. Entretanto, é preciso lembrar que a $\mathrm{EE}$ tem respaldo legal e que, antes mesmo dos retrocessos apontados sobre a BNCC, a inclusão no espaço escolar já apresentava problemas na sua real efetivação. Assim, é extremamente importante que os profissionais da área continuem direcionando seus estudos na busca de ferramentas, serviços e soluções educacionais, renovando as práticas pedagógicas para que toda população estudantil, que não consegue ser atendida pelos currículos padronizados, tenha acesso à aprendizagem (MOREIRA, BAUMEL, 2001; HITCHOOK et al., 2002).

Um bom ponto de partida é elaborar aulas que atendam às necessidades, capacidades e interesses de todos os alunos, levando em consideração que os espaços escolares possuem estudantes com características, personalidades e estilos cognitivos diversos (CHETENA, 2016). Dessa forma, a elaboração de aulas baseadas em um modelo que favoreça inclusão escolar no ensino de ciências é mais que importante, é fundamental e democrático (ZERBATO; MENDES, 2018), pois somente assim o direito a uma formação igualitária, que forme todos os estudantes para seu exercício da cidadania, será garantida.

\section{Interpretação qualitativa e quantitativa da revisão bibliográfica}

Para obtenção de uma visão geral da configuração atual da EE no país, foi necessário coletar dados do Censo 2019 (BRASIL, 2019). Esses dados ajudam a compreender a demanda proveniente da inserção de PcD, TGD e Altas Habilidades/Superdotação na educação regular do país.

Para pensar nos desafios da EE, é preciso ainda refletir sobre a escola pública, pois a maioria dos alunos com deficiência, TGD e altas habilidades/superdotação estão matriculados nas escolas da rede estadual, municipal e federal. Dados do Censo de 2019 mostram que, cerca de $84 \%$ dos alunos com deficiências estão matriculados em escolas públicas e, pouco mais de $15 \%$, na rede privada de ensino (Figura 2a). Dos alunos de escolas particulares, mais de $60 \%$ estão em classes exclusivas, ou seja, separados dos demais estudantes. Observa-se, aqui, que a maioria dos estudantes com deficiência, TGD e altas habilidades/superdotação estão alocadas na rede pública de ensino, sendo esse setor o que mais carece em infraestrutura e recursos (LEONARDO; BRAY; ROSSATO, 2009). Dessa maneira, esses alunos são os primeiros afetados com os inúmeros problemas enfrentados pela educação pública no Brasil (BRASIL, 2019). 
Figura 2. (a) Número de matrículas de alunos com deficiência, TGD ou altas habilidades/superdotação em classes comuns ou exclusivas distribuídas na rede pública e privada (b) Número de matrículas de alunos com deficiência, TGD e altas habilidades/superdotação em classes comuns ou exclusivas no ensino médio de 2015 a 2019.

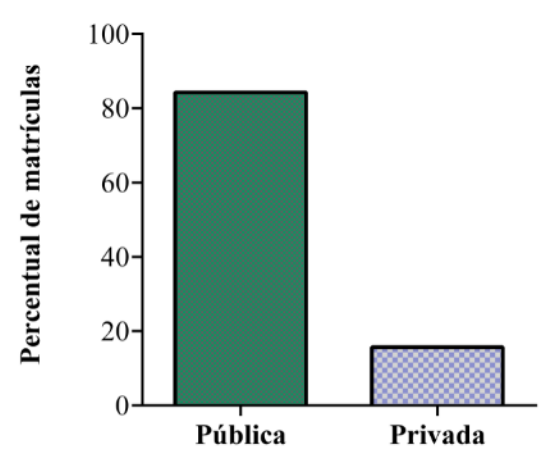

a)

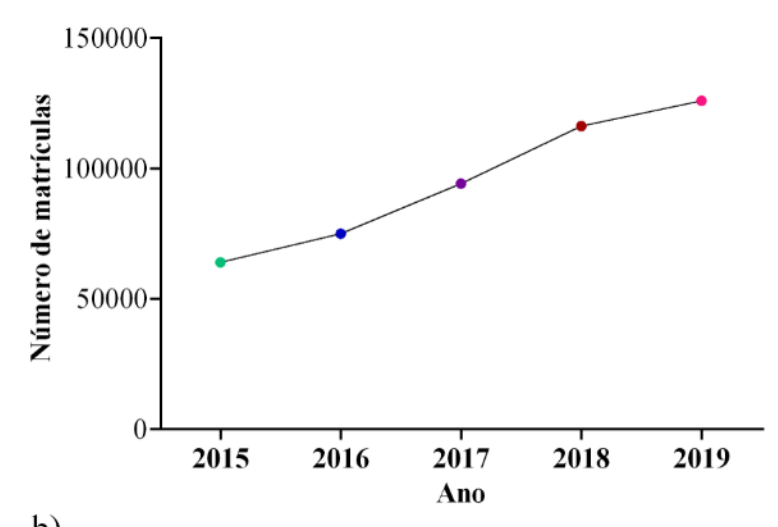

b)

Fonte: a) e b) Elaborado pelas autoras com base no Censo da Educação Básica (BRASIL, 2019).

Adicionalmente, é necessário pensar nos obstáculos pedagógicos que os professores e professoras enfrentam todos os dias nas salas de aulas, os quais são comuns na Educação regular e na EE, entretanto, tratando-se do ponto de vista inclusivo, esses obstáculos podem ser potencializados, influenciando negativamente a efetivação da EI. Como se não bastasse o fato de o currículo nacional não ter sido pensado para o alunado com deficiência, TGD e altas habilidades/superdotação, as escolas públicas também sofrem com a falta de recursos para implementação de práticas pedagógicas inclusivas (SANTOS, 2017). Além da falta de qualificação dos profissionais da educação na área de inclusão, o material didático não é nem um pouco funcional nas atividades (VIEIRA; MORAIS; GODINHO-NETO, 2019; GARCIA-REIS; GODOY, 2018). Enquanto as escolas públicas carecem de investimentos, as redes privadas contam com um arsenal de ferramentas e recursos, reafirmando a desigualdade esquecida na BNCC (GARCIA-REIS; GODOY, 2018).

Outros dados do Censo de 2019 revelam o crescente número de matrículas da EE que chegaram a 1,3 milhão, um aumento de 34,4\% em relação a 2015. Quando avaliado o número de matrículas, só no EM há mais de 125.000 (Figura 2b), indicando que o percentual de alunos com deficiência, TGD e altas habilidades/superdotação, matriculados em classes comuns, tem aumentado gradualmente para todas as etapas de ensino (BRASIL, 2019). Mas, a chegada de novos alunos e as recentes mudanças no currículo, possivelmente, causarão evasão dos estudantes em todas as etapas da educação. Para que isso não ocorra, é de extrema importância que os acadêmicos, professores e toda sociedade lutem por uma EI (ORRÚ, 2018), gerindo projetos pedagógicos diversos, inovadores e inclusivos com a finalidade de garantir o direito à educação de todos os integrantes da sociedade.

Os resultados apontam que o discurso hegemônico da BNCC dá margem à ampliação da desigualdade e exclusão; não há espaço para as minorias, dentre elas, o público-alvo da EE. $\mathrm{O}$ discurso de respeito à diversidade apenas aparece para respaldar os aspectos legais que levaram a sua consolidação (FERREIRA; MOREIRA; VOLSI, 2020). O caminho que os alunos com deficiência, TGD e altas habilidades/superdotação, que não fazem parte de classes privilegiadas, percorrerão durante sua trajetória acadêmica será tortuoso e alheio aos demais (GONÇALVES; MACHADO; CORREIA, 2020). Isso porque a BNCC não apresenta uma estrutura para garantir a permanência e qualidade social desse alunado (ORRÚ, 2018).

Além da análise anterior, a revisão bibliográfica, gerada a partir da busca pelas palavraschave: Base Nacional Comum Curricular, BNCC e Common National Curriculum Base, totalizou em 128 artigos dos mais diversos campos relacionados à educação, conforme explicitam as figuras $3 \mathrm{a}, 3 \mathrm{~b}$ e $3 \mathrm{c}$, colocadas a seguir: 
Figura 3. (a) Número de artigos publicados de 2014-2020 nas bases de dados Scielo, Scopus e Web of Science referentes a Base Nacional Comum Curricular. (b) Número de artigos encontrados nas bases de dados Scielo, Scopus e Web of Science referentes a Base Nacional Comum Curricular de 2014-2020. (c) Número de artigos agrupadas por área de conhecimento.
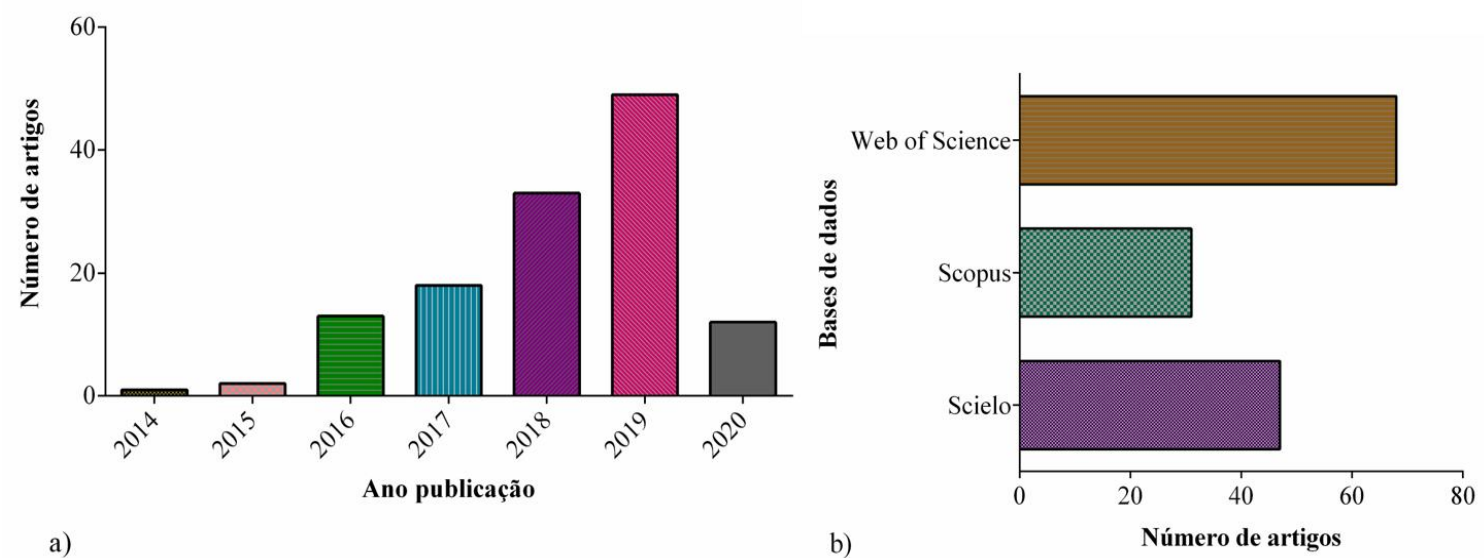

a)

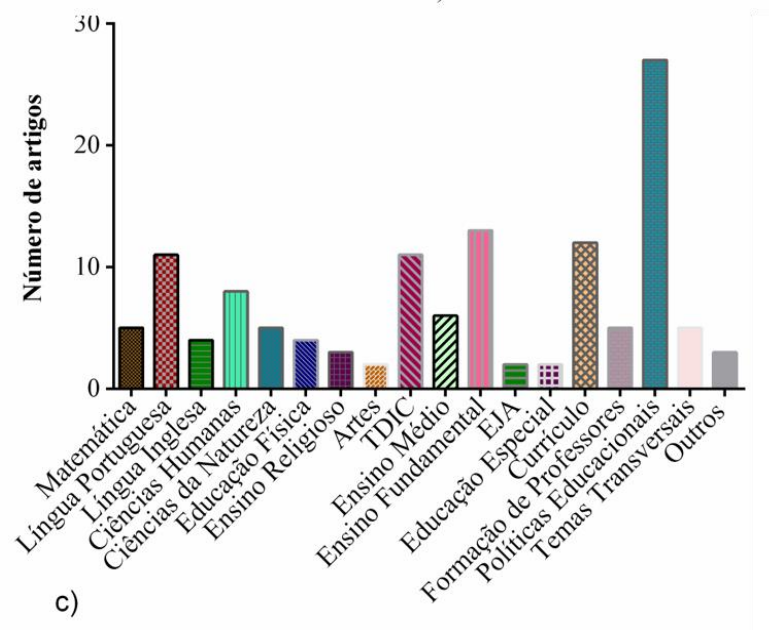

Fonte: Elaborado pelas autoras.

É crescente o número de publicações ao longo dos últimos anos, possuindo o ano de 2019 e 2020, aproximadamente, $47 \%$ do total dos artigos publicados até o momento (Figura 3a), isso se dá pelo fato de que a BNCC teve sua versão final homologada apenas em 2018 (BRASIL, 2018). Entretanto, os estudos anteriores ajudam a refletir sobre os processos de formulação que levaram a sua versão final, tais como: a mudança de governo em 2016, a participação de grupos empresariais, conservadores, entre outros, por exemplo, o estudo de Macedo (2017). A revisão também ajudou a compreender a distribuição dos artigos nas bases de dados utilizadas (Figura 3b), sendo a Web of Science aquela que contemplou o maior número de artigos encontrados (46\%), Scielo (32\%), Scopus (22\%). Os resultados demonstram a abrangência deste trabalho, propiciando uma pesquisa uniforme sobre o tema de interesse.

Além disso, foi possível obter um panorama global dos temas e áreas em que foram publicados, desde a proposta de uma Base Nacional até sua homologação (Figura 3c), sendo o campo de políticas públicas e educacionais o mais explorado pelos autores (ALMEIDA; JUNG, 2019; GALLO, 2017; LOURES; FREITAS, 2019; MACEDO, 2015, 2016, 2017). É notório observar a diversidade de campos que se relacionam com a BNCC, dentre eles, o de formação de professores e aspectos referentes ao Ensino Médio, Fundamental e Educação Infantil. Destaca-se, ainda, o grande número de estudos no campo de Língua Portuguesa (CARVALHO; CASTRO, 2017; CECHINEL, 2019; JARDIM; SAMPAIO; GALHARDO, 2019), de Tecnologias Digitais da Informação e Comunicação (CABRAL; LIMA; ALBERT, 2019; PINHO CAVALCANTI, 2020; FRANÇA; COSTA; SANTOS, 2019; FUZÂ; MIRANDA, 2020) e sobre Currículo (CARVALHO; CASTRO, 2017; MARCONDES, 2018).

Como o trabalho visa contribuir na área da EI, é importante destacar que, dentre todos os artigos, apenas dois documentos encontrados nessas bases (1,5\%) abordam a perspectiva 
da EE (ORRÚ, 2018; FERREIRA; MOREIRA; VOLSI, 2020) e nenhum deles faz menção ao ensino de $\mathrm{CN}$. Já em relação à temática $\mathrm{CN}$, foram encontrados cinco artigos (3,9\%): um aborda as questões inerentes aos componentes curriculares nos currículos de ciências, na primeira e segunda versão da BNCC (MARCONDES, 2018); outros três referem-se ao ensino de física no EM e a estratégias de ensino (RIBEIRO, 2016; SABINO et al., 2019; SILVA NETO; FREIRE JÚNIOR, 2017); o último debate sobre uma sequência pedagógica no Ensino de Jovens e Adultos (EJA) (VIEIRA; MORAIS; GODINHO-NETO, 2019).

Isso reflete bastante sobre o futuro do ensino de ciências no campo EI no Brasil. Dessa forma, este é o momento de refletir e pensar atitudes que possam contribuir para uma sociedade mais justa. Mercado e Fumes (2018) afirmam que:

\begin{abstract}
A ideia de Inclusão Escolar, regulamentada em leis e políticas educacionais está longe de se concretizar em práticas curriculares. Os estudantes com deficiência veem-se privados do acesso ao conhecimento e à cidadania, já que continuarão precisando de quem possa falar e pensar por eles. A construção de um currículo que assegure o acesso crítico ao mundo dos conhecimentos e o desenvolvimento de uma consciência cidadã, a qual lhe permita enfrentar os desafios do mundo contemporâneo, não está previsto na BNCC em discussão (2018, p. 13).
\end{abstract}

Como não está previsto formalmente na BNCC, o papel dos profissionais da educação e das entidades educacionais é reivindicar e criticar, contribuindo com estudos e, principalmente, com ferramentas que estimulem o ensino e aprendizagem do alunado com deficiência, TGD e altas habilidades/superdotação. É hora de os pesquisadores da área de Química, Física e Biologia refletirem sobre o papel das ciências na vida desses estudantes, pensando em soluções didáticas e mecanismos que facilitem a compreensão dos conceitos científicos e ajudem a formar cidadãos aptos a cumprirem seu papel na sociedade (MARCONDES, 2018).

Os diálogos estabelecidos entre os artigos da revisão, utilizando o software Iramuteq ${ }^{\circledR}$, permitiram produzir uma análise geral do corpus textual interpretativo e mais amplo. A nuvem de palavras criadas, a partir da análise dos resumos dos artigos, agrupou as palavras e as organizou graficamente em função da sua frequência (Figura 4).

Figura 4 - Nuvem de palavras mais recorrentes nos resumos dos artigos da revisão bibliográfica

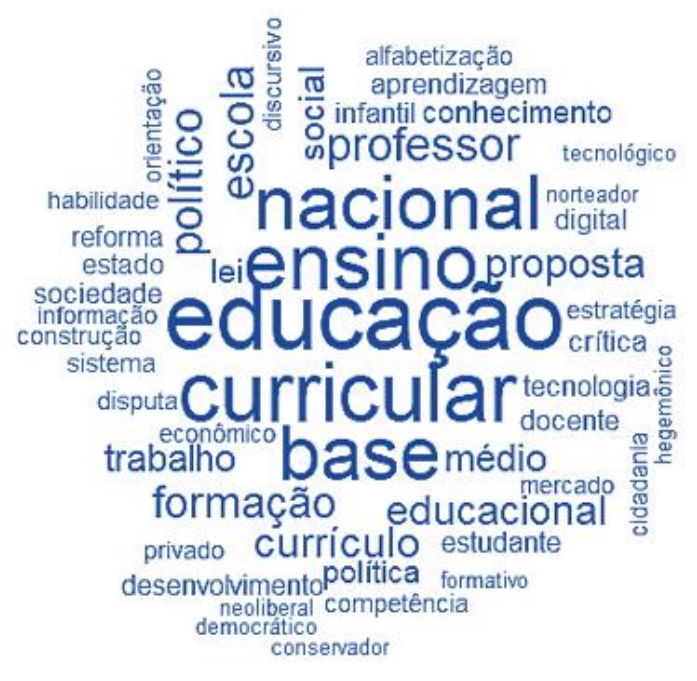

Fonte: Elaborado pelas autoras.

Observa-se que as palavras mais recorrentes nos resumos aparecem em maior tamanho e centralizadas, sendo elas: educação, ensino, base, nacional e curricular; estas se destacam por fazerem parte de todos os artigos estudados, primeiro, porque estão relacionadas a currículo e, segundo, porque todas pertencem aos campos da educação e ensino. Nota-se, ainda, a ausência de itens lexicais, como inclusão, EE e EI. Este mapa corrobora com o que se tem falado sobre a BNCC, mostrando a eficiência do software para análises de cunho documental (CAMARGO; JUSTO; 2013; MARTINS; TOSTES; MELLO, 2018). 
Figura 5. Análise de Similitude das palavras com as palavras mais recorrentes nos resumos dos artigos da revisão bibliográfica.

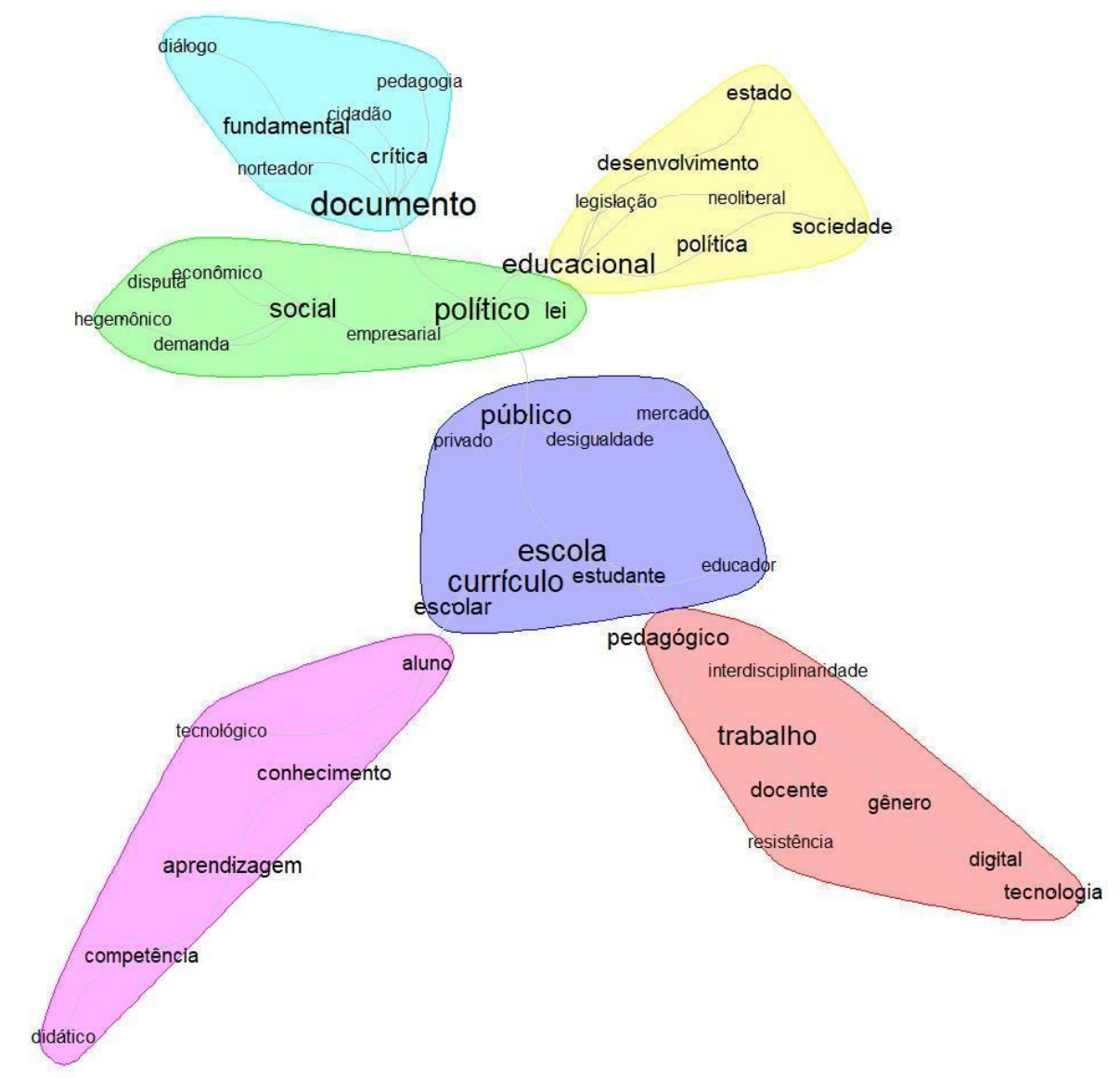

Fonte: Elaborado pelas autoras.

A análise de similitudes (Figura 5) está ancorada na teoria dos grafos ${ }^{3}$ (elementos combinatórios) e permite identificar as coocorrências entre as palavras e a conexão entre elas, auxiliando na identificação da estrutura do texto. Esses métodos combinados contribuem para compreender quais são as tendências, características e ausências de itens lexicais no material analisado. Nosso resultado demonstra as conexões entre seis blocos temáticos e, para gerálo, foi necessário excluir as palavras de maior recorrência (base, nacional, educação e ensino), pois estas estão presentes em praticamente todos os artigos, criando um ninho de relações, complexo e amplo, sendo impossível de analisar.

Os blocos dividem-se em: documento, educacional, político, escola, pedagógico e aluno. No bloco documento (azul-claro), agrupam-se as palavras cidadão, diálogo, pedagogia e norteador. Essas palavras expressam, de uma forma sucinta, a definição do que vem a ser a BNCC, segundo a própria definição do documento (BRASIL, 2018, p.7). A BNCC norteia a educação básica, com as habilidades e competências essenciais para a formação de um cidadão apto a cumprir seu papel na sociedade. As interconexões fazem total sentido e, através dela, é possível ter uma ideia do que venha ser a BNCC.

O bloco educacional (amarelo) é composto por legislação, política, estado, desenvolvimento, sociedade e neoliberal, agrupando os artigos que abordam a temática de políticas públicas (FREITAS, 2014). Já no bloco político (verde) é possível identificar uma temática de resistência aos pensamentos hegemônicos, disseminados pela nova base, relacionando-se com as palavras disputa, demanda, hegemônico, econômico, lei e empresarial, discussão abordada por Macedo (2016) e Gallo (2017).

O grupo com as palavras escola, currículo, público, desigualdade, mercado, estudante e educador (roxo) acaba por ser o centro da análise de similitude; esse fato está ligado aos vários artigos sobre currículo (MARCONDES, 2018; KIPPER; OLIVEIRA; GOMES, 2019; RODRIGUES, 2019) e ao enfrentamento das desigualdades, dialogam sobre a multiplicidade e o cerceamento da diversidade (ABRAMOWICZ; TEBET, 2017; COSSETIN, 2017). 
No bloco aluno (rosa), as palavras - conhecimento, tecnológico, aprendizagem e competência - compõem o grupo de artigos que abordam tanto a temática da inserção das TDIC como as ferramentas necessárias para atingir as competências e habilidades do currículo (CABRAL; LIMA; ALBERT, 2019; FUZÂ; MIRANDA, 2020; SABINO et al., 2019). As palavras didática, competência, aprendizagem e conhecimento atrelam-se nos estudos sobre as competências da BNCC e processos pedagógicos para sua implementação (CÂNDIDO; GENTILINI, 2017; SILVA NETO; FREIRE JÚNIOR, 2017).

O campo trabalho (vermelho) é constituído por pedagógico, gênero, docente, resistência, interdisciplinaridade e tecnologias digitais, valorizando a inserção dos temas transversais, como discussões de gênero, orientação sexual, raça e educação ambiental que foram ocultados na presente BNCC. Por isso, faz-se necessário um movimento de resistência de todos os docentes para inserção de temas que realmente ajudarão na formação dos estudantes (CARVALHO; CASTRO, 2017; FREIRE, 2018; RIOS; VIEIRA, 2020; PESSOA; HOELZIE, 2017; SILVA; MELO, 2018; VIEIRA; MORAIS; GODINHO-NETO, 2019).

A análise realizada foi importante para nortear as informações da busca bibliográfica de forma simples e compreensível. Através dela, conseguiu-se elencar os principais assuntos e questões que os autores da área de educação têm se dedicado a estudar e debater no que diz respeito à BNCC. O software Iramateq ${ }^{\circledR}$ mostrou-se bastante útil nesse aspecto, pois sua interface foi agradável e prática na realização das análises, ajudando a corroborar nossas discussões com as dos diferentes autores.

Finalmente, fazendo uma análise nas quatro versões da BNCC, tentou-se rastrear as palavras-chave ligadas à EE e Pessoas com deficiência, TGD e altas habilidades/superdotação: deficiência, deficientes, acessíveis, acessibilidade, Atendimento Educacional Especializado e EE (Figura 6).

Figura 6. Gráfico de barras com ocorrências de palavras-chave ligadas à EE e pessoas com deficiência, TGD e altas habilidades/superdotação nas quatro versões da BNCC apresentadas pelo MEC.

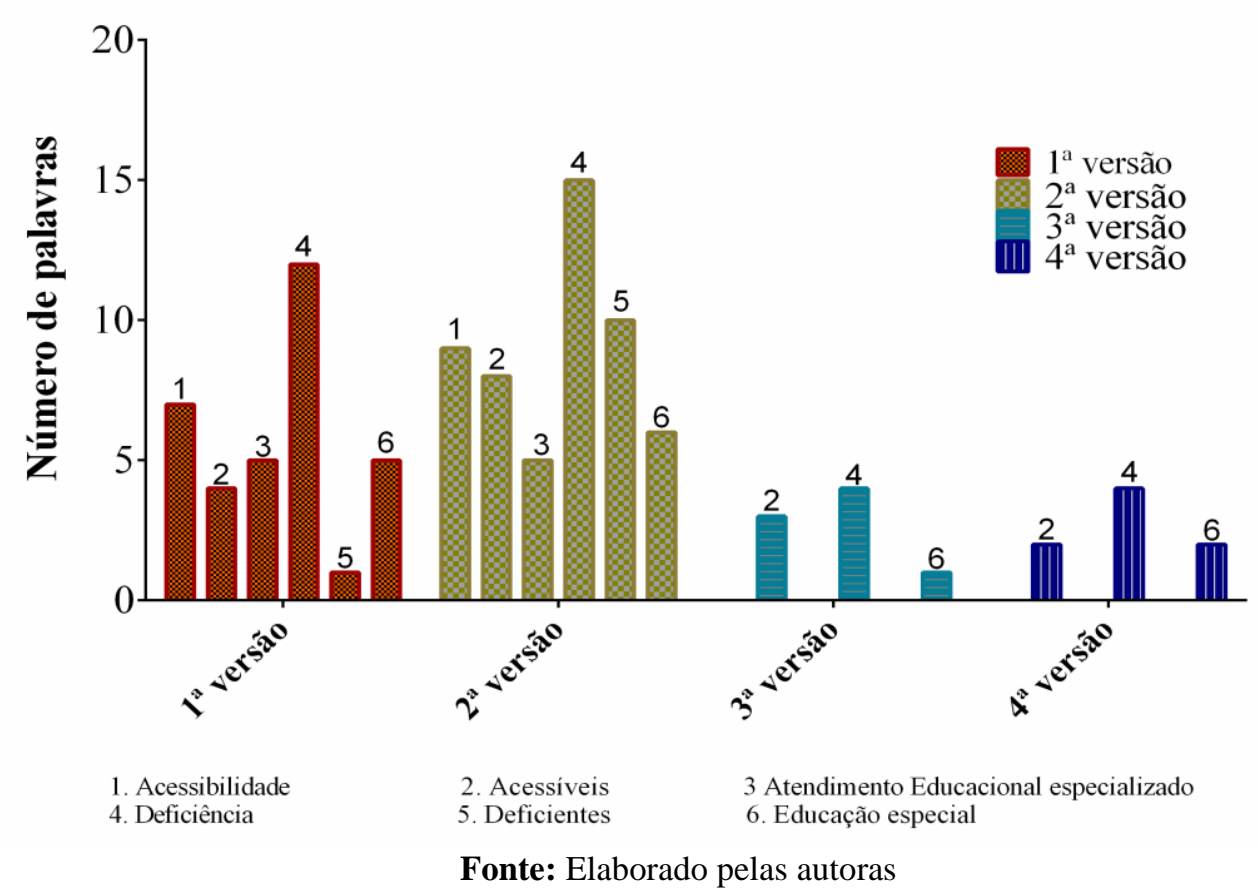

Comparando as quatro versões, observa-se que, nas duas primeiras, há maior ocorrência da palavra deficiência em relação às últimas versões; a palavra deficiente é mencionada uma única vez na primeira versão e dez na segunda, tendo abrupta queda de ocorrência na terceira e quarta versão com apenas quatro ocorrências.

Com relação às palavras EE, as duas primeiras versões apresentam uma seção dedicada à EE, por isso, palavras ligadas a essa modalidade, como AEE, acessibilidade e acessíveis são mais recorrentes, afirmando o compromisso dos formuladores em criar um currículo acessível que contemple todos os indivíduos. Em contraste, a última versão apresenta duas breves aparições das palavras EE, afirmando o dever das secretarias de adequarem seus currículos (BRASIL, 2018), porém, isso geraria diferenciação de sujeitos em razão da sua condição, levando à própria exclusão. 
As análises corroboram os resultados da revisão e com o que a literatura tem descrito: a BNCC foge do compromisso de atender os alunos com deficiência, TGD e altas habilidades/superdotação ao desconsiderar a presença desses indivíduos nos espaços educacionais. Assim, é essencial propor uma flexibilização curricular com estratégias e ferramentas pedagógicas que respeitem à diversidade e promovam a equidade para que tais mudanças beneficiem todos os indivíduos.

\section{Considerações finais}

Muitos são os desafios para afirmação de uma EI nas áreas das $\mathrm{CN}$, especialmente levando em conta o documento norteador que entrou em vigor sem projetos e suporte para efetivação da inclusão dos alunos e alunas com deficiência, transtornos globais do desenvolvimento e altas habilidades/superdotação.

Neste artigo, de modo geral, é explicitado o distanciamento entre o que uma base nacional deveria propor e o que ela realmente vem oferecer: uma educação sem o respeito à diversidade e sem aporte que sustente a Educação Especial. Se o documento se propõe como comum a todos os brasileiros, por que grupos minoritários não foram respeitados e cuidadosamente incluídos? A BNCC em suas seiscentas páginas deixa bem claro que sua intenção é universalizar o sujeito, criando um ritmo e velocidade que deve ser seguido para atingir as metas das avaliações internacionais. Muito embora não se proponha a incluir, acaba por criar uma política de homogeneização, excluindo aqueles que de alguma forma não correspondem às expectativas do capital.

Além do que foi exposto, o artigo amparou-se numa revisão bibliográfica nas principais bases de dados para análise qualitativa e quantitativa dos estudos publicados de 2014 até o presente momento, usando, para isso, gráficos e análise documental. Acredita-se veementemente que este estudo poderá contribuir para a compreensão geral da BNCC, bem como fará refletir sobre as políticas de EI no Brasil, principalmente no campo das CN. Essa discussão é de extrema importância para o direcionamento de pesquisas futuras sobre o EI. Espera-se que os estudiosos desloquem seus olhares para esse campo, para que todos tenham pleno acesso à educação, principalmente aqueles que por anos vêm sido esquecidos e ignorados nos currículos e práticas educacionais.

Para concluir a discussão, acredita-se que se farão necessários movimentos de resistência à BNCC, para que, de alguma forma, os órgãos públicos compreendam a necessidade de discutir o futuro da educação brasileira com a sociedade. Ademais, reforça-se a convocação dos profissionais da educação e pesquisadores da área de ensino em ciências para que se dediquem a pesquisas sobre a Base, buscando a produção de metodologias pedagógicas inclusivas nessa área. Somente assim, será possível diminuir os efeitos do documento na vida dos estudantes com deficiência, TGD e altas habilidades/superdotação.

Notas

1. Há um consenso entre os autores da área de ensino de CN inclusivo que a real efetivação de uma educação científica inclusiva é desafiadora, pois grande parte dos profissionais continuam seguindo metodologias tradicionais havendo a falta de estratégias pedagógicas diferenciadas; os cursos de licenciatura ainda carecem de uma reestruturação curricular que ofereça capacitação profissional para que os profissionais das áreas de $\mathrm{CN}$ estejam aptos a atenderem os alunos com deficiência, TGD e altas habilidades/superdotação; há a falta de infraestrutura nas escolas e escassez de materiais didáticos acessíveis (SCHENATO; STRIEDER, 2020; MARTINS, 2012; LIPPE; CAMARGO, 2009).

2. Iramuteq ${ }^{\circledR}$ é um software gratuito ligado ao pacote estatístico R para análises de dados textuais, como a lexicografia básica (cálculo de frequência de palavras), até análises multivariadas (classificação hierárquica descendente, análises de similitude). Foi desenvolvido em 2009 por Pierre Ratinaud no Laboratoire d'Études et de Recherches Appliquées en Sciences Sociales da Universidade de Toulouse na França

3. A teoria dos grafos é um ramo da matemática que estuda as relações entre os objetos de um determinado conjunto, ordenando pontos que são chamados de vértices e um conjunto de linhas denominadas arestas. Neste ordenamento, cada aresta está conectada em, pelo menos, um vértice. Com a ideia de pontos interligados por linhas, a representação por grafos pode facilitar o entendimento e a resolução de problemas, possuindo aplicabilidade em diversas áreas como engenharia, programação, análise lexical e ciências. 


\section{Referências}

ABRAMOWICZ, Anete; TEBET, Gabriela Guarnieri de Campos. Educação infantil: um balanço a partir do campo das diferenças. Pro-posições, v. 28, p. 182-203, 2017.

AGUIAR, Denise Brasil Alvarenga. A Construção da Autonomia do Professor de Português: Questões de Formação e Limites de Ação. Línguas \& Letras, v. 18, n. 39, p. 80-95, 2017.

ALMEIDA, Ivanete Bellucci Pires; BATISTA, Sueli Soares dos Santos. Educação profissional no contexto das reformas curriculares para o ensino médio no Brasil. EccoS Revista Científica, n. 41, p. 17-29, 2016.

ALMEIDA, Maria de Lourdes Pinto; JUNG, Hildegard Susana. Políticas curriculares e a base nacional comum curricular: emancipação ou regulação? Educação (UFSM), v. 44, p. 1-14, 2019.

BRANCO, Emerson Pereira; ROYER, Marcia Regina; GODOI BRANCO, Alessandra Batista. A abordagem da Educação Ambiental nos PCNS, nas DCNS e na BNCC. Nuances: estudos sobre Educação, v. 29, n. 1, p. 185-203, 2018.

BRANDÃO, Carlos Fonseca; TREVELIN, Fátima Gil de Oliveira. O "Programa Ler e Escrever" no contexto de uma escola municipal. Revista on line de Política e Gestão Educacional, v. 21, n. 1, p. 167-189, 2017.

BRASIL. Constituição da República Federativa do Brasil de 1988. Disponível em: http://www.planalto.gov.br/ccivil_03/constituicao/constituicao.htm. Acesso em: 14 abr. 2020.

BRASIL. Histórico da BNCC. Disponível http://www.planalto.gov.br/ccivil_03/constituicao/constituicao.htm. Acesso em: 10 jun. 2020.

em:

BRASIL. Instituto Nacional de Estudos e Pesquisas Educacionais Anísio Teixeira (2019). Censo da Educação Básica. Disponível em: http://portal.inep.gov.br/web/guest/censo-escolar. Acesso em: 14 abr. 2020.

BRASIL. Lei 13.005, de 25 de junho de 2014. Aprova o Plano Nacional de Educação. Disponível em: http://www.planalto.gov.br/ccivil_03/_Ato2011-2014/2014/Lei/L13005.htm. Acesso em: 14 abr. 2020.

BRASIL. Lei no 13.146, de 6 de julho de 2015. Institui a Lei Brasileira de Inclusão da Pessoa com Deficiência (Estatuto da Pessoa com Deficiência). Disponível em:http://www.planalto.gov.br/ccivil_03/_ato20152018/2015/lei/113146.htm. Acesso em: 14 abr. 2020.

BRASIL. Lei $\mathbf{n}^{\mathbf{0}}$ 13.415, de 16 de fevereiro de 2017. Disponível em: http://www.planalto.gov.br/ccivil_03/_ato2015-2018/2017/lei/113415.htm. Acesso em: 14 abr. 2020.

BRASIL. Lei 9.394, de 20 de dezembro de 1996. Estabelece as diretrizes e bases da educação nacional. Disponível em: http://portal.mec.gov.br/seesp/arquivos/pdf/lei9394_ldbn1.pdf Acesso:14 abr. 2020.

BRASIL. Ministério da Educação. Base Nacional Comum Curricular: $2^{\mathrm{a}}$ versão revista, 2017. Disponível em: http://basenacionalcomum.mec.gov.br/images/relatorios-analiticos/bncc-2versao.revista.pdf Acesso em: 05 jun. 2020.

BRASIL. Ministério da Educação. Base Nacional Comum Curricular: educação é a base, 2018. Disponível em: http://basenacionalcomum.mec.gov.br/images/BNCC_EI_EF_110518_versaofinal_site.pdf. Acesso em: 14 abr. 2020.

CABRAL, Ana Lúcia Tinoco; LIMA, Nelci Vieira; ALBERT, Sílvia. TDIC na educação básica: Perspectivas e desafios para práticas de ensino da escrita. Trabalhos em Linguística Aplicada, v. 58, n. 3, p. 1134$1163,2019$.

CAMARGO, Brigido Vizeu; JUSTO, Ana Maria. IRAMUTEQ: um software gratuito para análise de dados textuais. Temas em psicologia, v. 21, n. 2, p. 513-518, 2013.

CÂNDIDO, Rita de Kássia; GENTILINI, João Augusto. Base Curricular Nacional: reflexões sobre autonomia escolar e o Projeto Político-Pedagógico. Revista Brasileira de Política e Administração da EducaçãoPeriódico Científico editado pela ANPAE, v. 33, n. 2, p. 323-336, 2017.

CARVALHO, Isabela Bastos; CASTRO, Alexandre Carvalho. Currículo, racismo e o ensino de língua portuguesa: as relações étnico-raciais na educação e na sociedade. Educação \& Sociedade, v. 38, n. 138, p. 133-151, 2017.

CECHINEL, André. Semiformação Literária: a instrumentalização da literatura na nova BNCC. Educação \& Realidade, v. 44, n. 4, p. 1-13, 2019.

CHETENA, Natasha. Teaching Tips For an UDL-Friendly Classroom: Advice for implementing strategies based on Universal Design for Learning. Disponível em: https://www.insidehighered.com/blogs/ gradhacker/teaching-tips-udl-friendly-classroom Acesso em: 20 mai. 2020.

COSSETIN, Vânia Lisa Fischer. Uma leitura ambivalente sobre a adoção de uma base curricular nacional: para fazer justiça à reflexividade da filosofia da educação. Educar em Revista, n. 66, p. 295-311, 2017.

COSTA, Hugo Heleno Camilo; LOPES, Alice Casimiro. A contextualização do conhecimento no ensino médio: tentativas de controle do outro. Educação \& Sociedade, v. 39, n. 143, p. 301-320, 2018.

COSTA, Marilda de Oliveira; SILVA, Leonardo Almeida da. Educação e democracia: Base Nacional Comum Curricular e novo ensino médio sob a ótica de entidades acadêmicas da área educacional. Revista Brasileira de Educação, v. 24, p. 1-24, 2019. 
FERREIRA, Gesilaine Mucio; MOREIRA, Jani Alves da Silva; VOLSI, Maria Eunice França. Políticas de educação especial na perspectiva da educação inclusiva no Brasil: Em discussão a Base Nacional Comum Curricular (BNCC). Revista Inclusiones, v. 7, n. 1, p. 10-34, 2020.

FERREIRA, Windyz Brazão. O conceito de diversidade na BNCC- relações de poder e interesses ocultos. Retratos da Escola, v. 9, n. 17, p. 299-319, 2016.

FISTAROL, Caique Fernando da Silva; FISCHER, Adriana; WENRLICH, Rosana Clarice Coelho. A Base Nacional Comum Curricular e a formação de professores de língua inglesa: desafios e possibilidades. Revista on line de Política e Gestão Educacional, v. 23, n. 2, p. 341-355, 2019.

FLÔR, Cristhiane Carneiro Cunha; TRÓPIA, Guilherme. Um Olhar para o discurso da Base Nacional Comum Curricular em funcionamento na área de ciências da natureza. Horizontes, v. 36, n. 1, p. 144-157, 2018.

FRANÇA, Fabiane Freire; COSTA, Maria Luisa Furlan; DOS SANTOS, Renata Oliveira. As novas tecnologias de informação e comunicação no contexto educacional das políticas públicas. ETD - Educação Temática Digital, v. 21, n. 3, p. 645-661, 2019.

FRANGELLA, Rita de Cássia Prazeres. Um pacto curricular: o pacto nacional pela alfabetização na idade certa e o desenho de uma base comum nacional. Educação em Revista, v. 32, n. 2, p. 69-90, 2016.

FREIRE, Priscila. 'Ideologia de gênero' e a política de educação no Brasil: exclusão e manipulação de um discurso heteronormativo. Ex aequo, n. 37, p. 33-46, 2018.

FREIRE, Sofia. Um olhar sobre a inclusão. Revista de Educação, v. 16, n. 1, p. 5-20, 2008.

FREITAS, Fabrício Monte; SILVA, João Alberto da; LEITE, Maria Cecília Lorea. Diretrizes invisíveis e regras distributivas nas políticas curriculares da nova BNCC. Currículo sem Fronteiras, v. 18, n. 3, p. 857-870, 2018.

FREITAS, Luiz Carlos de. Os reformadores empresariais da educação e a disputa pelo controle do processo pedagógico na escola. Educação \& Sociedade, v. 35, n. 129, p. 1085-1114, 2014.

FUZA, Ângela Francine; MIRANDA, Flávia Danielle Sordi Silva. Tecnologias digitais, letramentos e gêneros discursivos nas diferentes áreas da BNCC: reflexos nos anos finais do ensino fundamental e na formação de professores. Revista Brasileira de Educação, v. 25, p. 1-16, 2020.

GALLO, Sílvio. Biopolítica e subjetividade: resistência? Educar em Revista, n. 66, p. 77-94, 2017.

GARCIA-REIS, Andreia Rezende; GODOY, ARGL. O ensino de leitura nos anos iniciais do ensino fundamental: a proposta da Base Nacional Comum Curricular. Currículo sem Fronteiras, v. 18, n. 3, p. 1025-1043, 2018.

GIROTTO, Eduardo Donizeti. Dos PCNs a BNCC: o ensino de Geografia sob o domínio neoliberal. Geo Uerj, n. 30, p. 419-439, 2017.

GIROTTO, Eduardo Donizeti. Pode a política pública mentir? A Base Nacional Comum Curricular e a disputa da Qualidade educacional. Educação \& Sociedade, v. 40, p. 1-21, 2019.

GLAT, Rosana; PLETSCH, Márcia Denise; FONTES, Rejane de Souza. Educação inclusiva \& educação especial: propostas que se complementam no contexto da escola aberta à diversidade. Educação, v. 32, n. 2, p. 343-355, 2007.

GONÇALVES, Rafael Marques; MACHADO, Tânia Mara Rezende; CORREIA, Maria José Nascimento. A BNCC na contramão das demandas sociais: Planejamento com e planejamento para. Práxis Educacional, v. 16, n. 38, p. 338-351, 2020.

HITCHCOCK, Chuck et al. Fornecendo novo acesso ao currículo geral: Desenho universal para a aprendizagem. Ensinar filhos excepcionais, v. 35, n. 2, p. 8-17, 2002.

JARDIM, Alyne Souza; SAMPAIO, Juliano Casimiro Camargo; GALHARDO, Irma. O letramento literário: a literatura escolarizada. Dialogia, v. 32, p. 307-320, 2019.

KIPPER, Daiane.; OLIVEIRA, Cláudio José; GOMES, Luiza Bittencourt. Competências matemáticas na BNCC: Implicações curriculares. Práxis Educacional, v. 15, n. 34, p. 53-74, 2019.

KRIPKA, Rosana; SCHELLER, Morgana; BONOTTO, Danusa Lara. Pesquisa documental: considerações sobre conceitos e características na pesquisa qualitativa. CIAIQ2015, v. 2, p. 243-247, 2015.

LEMOS, Guilherme Augusto Rezende Lemos. Transposição didática: conhecimento, afeto e circunstância. Práxis Educacional, v. 15, n. 33, p. 48 -68, 2019.

LEONARDO, Nilza Sanches Tessaro; BRAY, Cristiane Toller; ROSSATO, Solange Pereira Marques. Inclusão escolar: um estudo acerca da implantação da proposta em escolas de ensino básico. Revista Brasileira de Educação Especial, v. 15, n. 2, p. 289-306, 2009.

LIMA, Marcelo; MACIEL, Samanta Lopes. A reforma do Ensino Médio do governo Temer: corrosão do direito à educação no contexto de crise do capital no Brasil. Revista Brasileira de Educação, v. 23, p. 1-25, 2018.

LIPPE, Eliza Márcia Oliveira; CAMARGO, E. P. Análise da formação inicial de professor de Ciências e Biologia frente ao desafio da inclusão escolar: uma questão curricular. Bauru: Unesp, v. 1, n. 1, p. 1-12, 2009.

LOURES, Débora Alves Morra; FREITAS, Victor Gonçalves. Projeto político pedagógico como instrumento de gestão democrática: Uma análise do município de Mendes-RJ. Humanidades \& Inovação, v. 6, n. 9, p. 77-87, 2019. 
MACEDO, Elizabeth. As demandas conservadoras do movimento escola sem partido e a base nacional curricular comum. Educação \& Sociedade, v. 38, n. 139, p. 507-524, 2017.

MACEDO, Elizabeth. Base Nacional Comum para currículos: direitos de aprendizagem e desenvolvimento para quem? Educação Sociedade, v. 36, n. 133, p. 891-908, 2015.

MACEDO, Elizabeth. Base Nacional Curricular Comum: a falsa oposição entre conhecimento para fazer algo e conhecimento em si. Educação em Revista, v. 32, n. 2, p. 45-68, 2016.

MARCONDES, Maria Eunice Ribeiro. As Ciências da Natureza nas $1^{\mathrm{a}}$ e $2^{\mathrm{a}}$ versões da Base Nacional Comum Curricular. Estudos Avançados, v. 32, n. 94, p. 269-284, 2018.

MARTINS, Lúcia de Araújo Ramos. Reflexões sobre a formação de professores com vistas à educação inclusiva. O professor e a educação inclusiva: formação, práticas e lugares. EDUFBA, p. 25-38, 2012.

MARTINS, Rodrigo Lema Del Rio; TOSTES, Luiza Fraga; MELLO, André Silva. Educação infantil e formação docente: análise das ementas e bibliografias de disciplinas dos cursos de educação física. Movimento (ESEFID/UFRGS), v. 24, n. 3, p. 705-720, 2018.

MELO, Alessandro de; MAROCHI, Ana Claudia. Cosmopolitismo e performatividade: Categorias para uma análise das competências na Base Nacional Comum Curricular. Educação em Revista, v. 35, p. 1-23, 2019.

MERCADO, Elisangela Leal de Oliveira; FUMES, Neiza de Lourdes Frederico. Base Nacional Comum Curricular e a Educação Especial no contexto da Inclusão Escolar. Encontro Internacional de Formação de Professores e Fórum Permanente de Inovação Educacional, v. 10, n. 1, p. 1-16, 2017.

MOREIRA, Laura Ceretta; BAUMEL, Roseli C. Currículo em educação especial: Tendências e debates. Educar em Revista, n. 17, p. 125-137, 2001.

NEIRA, Marcos Garcia; JÚNIOR, Wilson Alviano; ALMEIDA, Déberson Ferreira. A primeira e segunda versões da BNCC: construção, intenções e condicionantes. EccoS Revista Científica, n. 41, p. 31-44, 2016.

NETO, Alaim Souza. O Que são os PCN? O que afirmam sobre a literatura?.Debates em Educação, v. 6, n. 12, p. 112-128, 2014.

ORRÚ, Sílvia Ester. Base Nacional Comum Curricular: à Contramão dos Espaços de aprendizagem inovadores e inclusivos. Revista Tempos E Espaços Em Educação, v. 11, n. 25, p. 139-152, 2018.

PASSOS, Cármen Lúcia Brancaglion; NACARATO, Adair Mendes. Trajetória e perspectivas para o ensino de Matemática nos anos iniciais. Estudos Avançados, v. 32, n. 94, p. 119-135, 2018.

PEREIRA, Rodrigo da Silva. Governança corporativa da política educacional: o papel da OC. Revista Práxis Educacional, v. 15, n. 31, p. 123-146, 2019.

PESSOA, Rosane Rocha; HOELZLE, Maria José. Ensino de línguas como palco de política linguística: mobilização de repertórios sobre gênero. Trabalhos em Linguística Aplicada, v. 56, n. 3, p. 781-800, 2017.

PINHO CAVALCANTI, Larissa. Mídia e diversidade na escola: formação cidadã e os multiletramentos. Educação (UFSM), v. 45, p. 1-19, 2020.

PONCIANO, Jéssica Kurak et al. A" Base Nacional Comum Curricular" e a lei n 13.415/2017: educação dos jovens brasileiros de volta aos "anos de chumbo". Educação (UFSM), v. 44, p. 39-1-22, 2019.

PORTELA, Mugiany Oliveira Brito. A BNCC para o ensino de Geografia: A proposta das ciências humanas e da interdisciplinaridade. Geografia em debate, v. 12, n. 1, p. 48-68, 2018.

RIBEIRO, Jair Lúcio Prados. Cosmográficos: representando o espaço ao longo do tempo. Revista Brasileira de Ensino de Física, v. 38, n. 4, p. 1-10, 2016.

RIOS, Pedro Paulo Souza; VIEIRA, André Ricardo Lucas. The emerging of a gender discourse in education: the differences in the school space. Revista Tempos e Espaços em Educação, v. 13, n. 32, p. 1-17, 2020.

SABINO, Ana Claudia et al. A utilização do software Maxima no ensino por investigação da evolução estelar utilizando simulação gráfica da fusão nuclear. Revista Brasileira de Ensino de Física, v. 41, n. 3, 2019.

SANCHES, Isabel; TEODORO, António. Da integração à inclusão escolar: cruzando perspectivas e conceitos. Revista Lusófona de educação, n. 8, p. 63-83, 2006.

SANTOS, Luciola Licinio. Administrando o currículo ou os efeitos da gestão no desenvolvimento curricular. Educação em Revista, v. 33, p. 1-22, 2017.

SAVIANI, Demerval. Educação escolar, currículo e sociedade: o problema da Base Nacional Comum Curricular. Movimento-revista de educação, n. 4, p. 54-84, 2016.

SCHINATO, Liliani Correia Siqueira; STRIEDER, Dulce Maria. Ensino de Ciências na perspectiva da educação inclusiva: A importância dos recursos didáticos na prática pedagógica. Revista Temas em Educação, v. 29, n. 2, 2020.

SILVA NETO, Climério Paulo da; FREIRE JÚNIOR, Olival. Um Presente de Apolo: lasers, história e aplicações. Revista Brasileira de Ensino de Física, v. 39, n. 1, p. 1-10, 2017.

SILVA, Erivanildo Lopes; MARCONDES, Maria Eunice Ribeiro. Visões de contextualização de professores de química na elaboração de seus próprios materiais didáticos. Ensaio Pesquisa em Educação em Ciências, v. 12, n. 1, p. 101-117, 2010.

SILVA, Rafaela Campos Duarte; MELO, Savana Diniz Gomes. ENEM: propulsão ao mercado educacional brasileiro no século XXI. Educação \& Realidade, v. 43, n. 4, p. 1385-1404, 2018. 
SILVA, Tomaz Tadeu. Documento de identidade: uma introdução às teorias do currículo. Belo Horizonte, Autêntica, $3^{\circ}$ Edição, Editora Autêntica, 2010.

VIEIRA, William Kleber Martins; MORAES, Roberta Conceição Silva; GODINHO-NETTO, Martha Cristina Motta. Avaliação de uma sequência de ensino investigativa sobre poluição aplicada no Ensino Médio de alunos jovens e adultos. Comunicações, v. 26, n. 2, p. 161-177, 2019.

ZERBATO, Ana Paula; MENDES, Enicéia Gonçalves. Desenho universal para a aprendizagem como estratégia de inclusão escolar. Educação Unisinos, v. 22, n. 2, p. 147-155, 2018.

\section{Correspondência:}

Thalisia Cunha dos Santos: É mestranda do Programa de Pós Graduação em Química de Produtos Naturais na UFRJ e licenciada em química pela UFF. Atualmente, desenvolve projeto de pesquisa no Laboratório de Produtos Naturais de Algas Marinhas (ALGAMAR) com linha de atuação em química de produtos naturais de algas marinhas e cultivo in vitro e no Núcleo de Estudos e Pesquisa em Autismo (NEPA).

E-mail: thalisiacunhaq@gmail.com

Johana Marcela Concha Obando: Bióloga formada na Universidade de Nariño-Colômbia; com experiência de investigação na área de biotecnologia, biologia molecular e microbiologia. Mestre em Biologia Marinha e Ambientes Costeiros da Universidade Federal Fluminense (2018). Atualmente é doutoranda no Programa de Pós Graduação de Biologia Marinha e Ambientes Costeiros e faz parte do grupo de pesquisa ALGAMAR com linha de atuação em química, biossíntese de produtos naturais e cultivo in vitro de macroalgas marinhas.

E-mail: mc1226@gmail.com

Diana Negrão Cavalcanti: Professora da Universidade Federal Fluminense (UFF) é atual Coordenadora de Pós-graduação do Curso de Mestrado Profissional em Diversidade e Inclusão (CMPDI/UFF). Licenciada em Ciências Biológicas, especialista em Bioquímica, mestre e doutora em Química Orgânica (UFRJ/2004). Leciona na graduação, tanto na licenciatura quanto em bacharelado e na Pós-graduação em diferentes programas (Biologia Marinha e Ambientes Costeiros - PBMAC, Ciência, Tecnologia e Inclusão (PGCTIn) e Mestrado Profissional em Diversidade e Inclusão - CMPDI). Atualmente, vem desenvolvendo pesquisas translacionais envolvendo o Transtorno do Espectro do Autismo. Coordena o Núcleo de Estudos e Pesquisa em Autismo da UFF (NEPA) e é co-fundadora da Associação Caminho Azul (instituição em prol do desenvolvimento de pessoas com autismo).

E-mail: dn.cavalcanti@gmail.com

Texto publicado em Currículo sem Fronteiras com autorização das autoras 